\title{
Improvement of intestinal microflora balance by polysaccharide from Physalis alkekengi var. francheti
}

\author{
XINLI LI ${ }^{1}$, GUANG YANG ${ }^{1}$, CUILI ZHANG ${ }^{1}$, DACHANG WU ${ }^{1}$, LI TANG $^{2}$ and YI XIN ${ }^{1}$ \\ Departments of ${ }^{1}$ Biotechnology and ${ }^{2}$ Microecology, Dalian Medical University, Dalian, Liaoning 116044, P.R. China
}

Received June 13, 2013; Accepted November 22, 2013

DOI: $10.3892 / \mathrm{mmr} .2013 .1835$

\begin{abstract}
A water-soluble polysaccharide fraction (PPSB) was fractionated from Physalis alkekengi var. francheti and purified using DEAE-52 Cellulose and Sephadex G-200 chromatography. The physicochemical properties of PPSB and its molecular activities involved in the improvement of intestinal microflora balance were evaluated. PPSB (12.5-25.0 mg/ml) was shown to promote the growth of Lactobacillus delbrueckii and to inhibit the growth of Escherichia coli. Denaturing gradient gel electrophoresis analysis identified Bacteroides, Lactobacillus, Helicobacter, Prevotella, Enterococcus, Odoribacter, Alistipes and Akkermansia as dominant organisms in the intestinal tract of mice. PPSB exhibited stimulatory effects on the growth of probiotic bacteria but inhibitory effects on the growth of pathogenic bacteria in vitro. The number of species and quantity of the Lactobacillus genus increased significantly with increasing concentrations of PPSB in vivo. Experimental results of this study suggest that PPSB may improve intestinal microflora imbalances and therefore has strong potential as a natural agent for restoring the intestinal microflora balance.
\end{abstract}

\section{Introduction}

Physalis alkekengi var. francheti of the Solanaceae family is a well-known edible and medicinal plant used in Northeastern regions of China. Its fruit calyx has been used in traditional Chinese medicine as a therapeutic agent for removing fever or inflammation and toxic materials and relieving sore throats (1). It has great potential and development of a stable form of $P$. alkekengi var. francheti as a product may fulfill the requirements of the health food market. Studies on $P$. alkekengi var. francheti have attracted increased attention in recent years due to its potential biological functions. In addition, the active components of this plant, including physalins, polysaccharides and flavones, have been widely studied (2-5).

Correspondence to: Professor Yi Xin, Department of Biotechnology, Dalian Medical University, No. 9, West-Middle Section of Lushun South Road, Dalian, Liaoning 116044, P.R. China E-mail: jimxinbio@gmail.com

Key words: Physalis alkekengi var. francheti, PPSB, intestinal microflora balance, growth curves, denaturing gradient gel electrophoresis
However, to the best of our knowledge, no studies have analyzed the improvement of intestinal microflora balance using $P$. alkekeng $i$ var. franchet $i$. Therefore, the present study focused on the structure of the polysaccharide fraction [designated $P$. alkekengivar. francheti polysaccharide B (PPSB) hereafter], which may improve the intestinal microflora balance and evaluated the effects of PPSB on intestinal bacteria in vitro and in vivo. The objectives of this study were to investigate the isolation and characterization of PPSB from the fruit calyx of $P$.alkekengi var. franchet $i$ and to analyze its effects on intestinal microflora in vitro and in vivo. PPSB showed stimulatory effects on the growth of probiotic bacteria and inhibitory effects on that of pathogenic bacteria. Denaturing gradient gel electrophoresis (DGGE) was combined with image analysis to provide insight into the microbial similarities and diversity of the sites, while construction of an unweighted pair group method with arithmetic mean (UPGMA) dendrogram $(6,7)$ and sequencing (8) were conducted to test for DGGE motifs and taxa.

\section{Materials and methods}

Materials and chemicals. Calyces of P. alkekengi var. franchet $i$ were purchased from Dalian Traditional Chinese Medicine Market (Dalian, China) in October 2011 and identified according to the identification standard of Pharmacopeia of the People's Republic of China (9). A voucher specimen (no. LP201101) was deposited in the Department of Biotechnology, Dalian Medical University, Dalian, China.

DEAE-52 Cellulose was purchased from Whatman International Ltd. (Maidstone, Kent, UK). Sephadex G-200 was purchased from Pharmacia Co. (Stockholm, Sweden) and the E.Z.N.A ${ }^{\circledR}$ Stool DNA kit was purchased from Omega Bio-tek, Inc. (Norcross, GA, USA). Polymerase chain reaction primers, GC-357f, 518r and 357f (10) (Table I), were synthesized by Takara Biotechnology (Dalian) Co., Ltd. (Dalian, China). All other chemical reagents used were of analytical grade.

Isolation and purification of PPSB. The air-dried calyces of $P$. alkekengi var. francheti $(3.0 \mathrm{~kg})$ were extracted four times at $85^{\circ} \mathrm{C}$ using distilled water (30 liters), for $3 \mathrm{~h}$ each time. Each extract was filtered, concentrated and centrifuged (HC-3018 R High speed refrigerated centrifuge; Zhongke Zhongjia Scientific Instrument Co., Ltd., Anhui, China), prior to treating the supernatant with three volumes of ethanol at $4^{\circ} \mathrm{C}$ overnight. The crude polysaccharides precipitated by ethanol were 
Table I. Nucleotide sequences of primers.

Primer

Sequence 5'-3'

GC-357f

$518 \mathrm{r}^{\mathrm{b}}$

$357 \mathrm{f}^{\mathrm{a}}$

\author{
CGCCCGGGGCGCGCCCCGGGCGGGGCGGGGGACGGGGGGCCTACGGGAGGCAGCAG \\ ATTACCGCGGCTGCTGG \\ CCTACGGGAGGCAGCAG
}

${ }^{\mathrm{a}}$ Forward; ${ }^{b}$ reverse.

washed with dehydrated alcohol and diethyl ether, collected by centrifugation and dried under reduced pressure. The sample was dissolved in distilled water and frozen at $-20^{\circ} \mathrm{C}$, thawed at room temperature and centrifuged at $9,000 \mathrm{x}$ g for $20 \mathrm{~min}$ to remove insoluble materials. Crude polysaccharide was precipitated with $50 \%$ ethanol and the supernatant was recovered by centrifugation. The polysaccharide fraction, termed PPS, was obtained from the supernatant by precipitation using $70 \%$ ethanol $(4,11)$. P. alkekengivar.francheti polysaccharide A (PPSA) was deproteinated by a combination of proteinase and the Sevag method (12). Dissolved PPSA was fractionated on a DEAE-52 cellulose column $(1.5 \times 90 \mathrm{~cm})(13)$. The column was eluted first with distilled water and then with a gradient solution $(0.1,0.25$ and $0.5 \mathrm{~mol} / 1 \mathrm{NaCl} ; 0.5 \mathrm{~mol} / 1 \mathrm{NaOH})$ at a flow rate of $0.5 \mathrm{ml} / \mathrm{min}$. The major polysaccharide fractions were collected and concentrated and residues were loaded onto a Sephadex G-200 gel column $(1.5 \times 90 \mathrm{~cm})$. The column was eluted with $0.1 \mathrm{~mol} / \mathrm{l} \mathrm{NaCl}$ at a flow rate of $0.5 \mathrm{ml} / \mathrm{min}$ and the main polysaccharide fraction (PPSB) was collected, dialyzed (MD 34 dialysis tube; Solarbio Co., Ltd. Beijing, China) and lyophilized (FD-1A-50 lyophilizer; Bilang Instrument Co., Ltd., Shanghai, China) for further analysis. Each fraction was monitored with the phenol sulfuric acid method using glucose as a standard (14).

Physicochemical properties of PPSB. The total carbohydrate content of PPSB was determined by the phenol-sulfuric acid colorimetric method and protein content was quantified using the Bradford method (15).

\section{In vitro effects on the intestinal bacterium}

Experimental bacterial strains. Strains of L. delbrueckii ATCC 7830 and E. coli ATCC 25922 were supplied by the Department of Biotechnology, Dalian Medical University (Dalian, China).

Growth curves. L. delbrueckii ATCC 7830 and E. coli ATCC 25922 belong to the families Lactobacillaceae and Enterobacteriaceae, respectively, which are common and important intestinal microflora. The strains were cultured in DeMan-Rogosa-Sharpe (MRS) and LB mediums, respectively, and the mediums were autoclaved at $115^{\circ} \mathrm{C}$ for $15 \mathrm{~min}$.

The effects of PPSB on the growth of L. delbrueckii were analyzed using 96-well microplates (16). Subsequent to this, $100 \mu \mathrm{l}$ MRS inoculated broth $\left(2.25 \times 10^{6} \mathrm{cfu} / \mathrm{ml}\right)$ was added to each well and $100 \mu 1$ PPSB was added to the first well of each column for testing. A 2-fold serial dilution was performed using a multichannel micropipette to produce final concentrations of $0.20-25.0 \mathrm{mg} / \mathrm{ml}$. The microplates were incubated at $37^{\circ} \mathrm{C}$ for $28 \mathrm{~h}$ and the optical density values were calculated at intervals of $2 \mathrm{~h}$ at $595 \mathrm{~nm}$ (Thermo Labsystem MK3 Microplate Reader; Thermo Fisher Scientific, Waltham, MA, USA).

The effects of PPSB on the growth of E. coli were analyzed using the same procedure but with $100 \mu \mathrm{LB}$ inoculated broth $\left(1.25 \times 10^{6} \mathrm{cfu} / \mathrm{ml}\right)$ added to each well.

\section{In vivo effects on the intestinal microflora}

Experimental animals. Female BALB/c mice weighing $20 \pm 2 \mathrm{~g}$, purchased from the Animal Experimental Center of Dalian Medical University [certificate of quality number, SCXK (Liao) 2008-0002], were used for this study. The mice were kept under standardized conditions at a temperature of $22-24^{\circ} \mathrm{C}, 20 \%$ humidity and $12 \mathrm{~h}$ light/dark cycle. The mice had free access to a standard diet and water (ad libitum) and were allowed to acclimatize for five days prior to the start of the experiments. The study was approved by the Ethics Committee of Dalian Medical University (Dalian, China).

Antibiotic-induced intestinal microflora imbalance model in mice. Intestinal microflora imbalance was induced by intragastric (i.g.) administration of $65 \mathrm{mg} / \mathrm{kg}$ levofloxacin dissolved in water for five days (17).

Experimental design. Sixty mice were randomly divided into six groups (10 mice per group): 1, levofloxacin control (LC) with normal mice treated with levofloxacin; 2, PPSB-L with levofloxacin-treated mice with $50 \mathrm{mg} / \mathrm{kg}$ PPSB; 3, PPSB-H with levofloxacin-treated mice with $100 \mathrm{mg} / \mathrm{kg}$ PPSB; 4 , normal control (NC) with normal mice treated with water; 5 , N-PPSB-L with normal mice with $50 \mathrm{mg} / \mathrm{kg}$ PPSB and 6, N-PPSB-H with normal mice with $100 \mathrm{mg} / \mathrm{kg}$ PPSB.

All groups received i.g. injection once per day. Food and water consumption and body weight were recorded daily. Following seven days of treatment, fecal matter was collected and preserved at $-80^{\circ} \mathrm{C}$.

Deoxyribonucleic acid (DNA) extraction. DNA was extracted from fecal samples using an E.Z.N.A ${ }^{\circledR}$ Stool DNA kit (Omega Bio-tek, Inc.) in accordance with the manufacturer's instructions. The quantity and type of DNA extracts were analyzed by electrophoresis of $1 \%$ agarose gel containing ethidium bromide and compared with a molecular weight standard $(1 \mathrm{~kb})$. The DNA concentration was measured spectrophotometrically using the BioPhotometer plus (NanoVue Plus, GE Healthcare, Cleveland, OH, USA) and DNA extracts were preserved at $20^{\circ} \mathrm{C}$.

PCR amplification. Primers GC-357f and 518r were used to amplify the V3 region of bacterial 16S rRNA. PCR amplification was performed using an automated thermocycler (Thermo Fisher Scientific) as follows: $3 \mu$ purified genomic DNA as template ( 300 ng), $2.5 \mu 1$ 10X Ex Taq buffer $\left(\mathrm{Mg}^{2+}\right)$, 

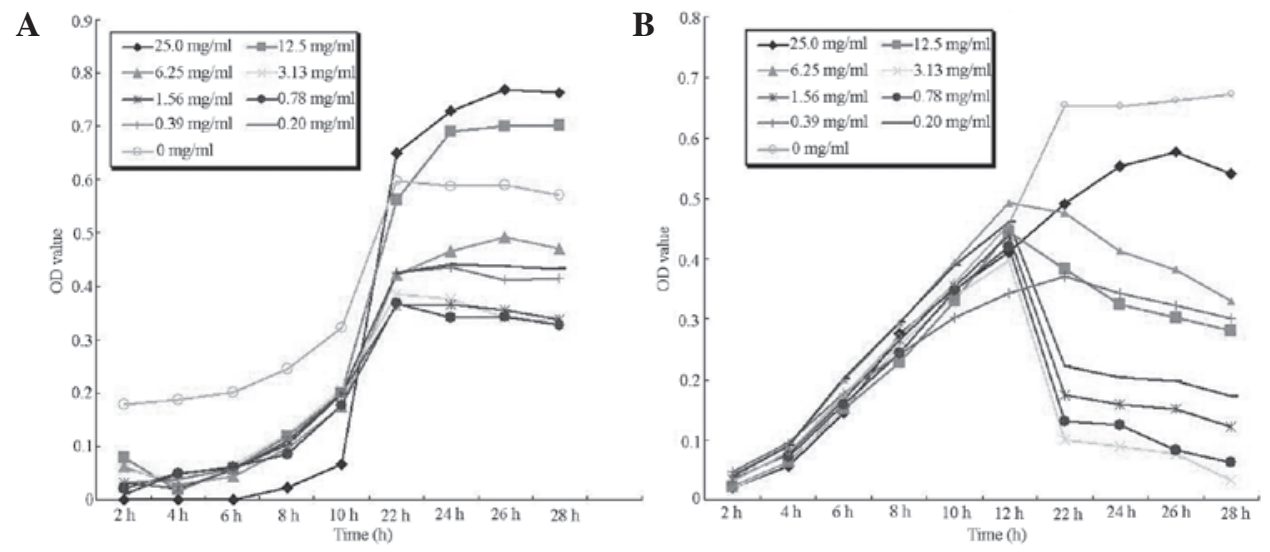

Figure 1. Growth curves of (A) L. delbrueckii and (B) E. coli of varying P. alkekengivar.francheti polysaccharide B (PPSB) concentrations.

$4 \mu \mathrm{dNTP}$ mixture, $2.5 \mu 1$ bovine serum albumin $(1 \mathrm{mg} / \mathrm{ml})$, 10 pmol each primer and 1.25 units Ex Taq polymerase [Takara Biotechnology (Dalian) Co., Ltd.], filled up to a volume of $25 \mu \mathrm{l}$ with sterile Milli-Q water. The thermal program consisted of an initial denaturation at $94^{\circ} \mathrm{C}$ for $5 \mathrm{~min}$, followed by 30 cycles of 94,54 and $72^{\circ} \mathrm{C}$ for $30 \mathrm{sec}$ each, in which the annealing temperature was $72^{\circ} \mathrm{C}$ for $7 \mathrm{~min}$ (18). Amplification products were analyzed initially by electrophoresis of a $1 \%$ agarose gel containing ethidium bromide and compared with a molecular weight standard (100 bp).

$D G G E$ analysis. DGGE was performed using the $\mathrm{D}-$ Code $^{\mathrm{TM}}$ Universal Mutation Detection system (Bio-Rad, Hercules, CA, USA). PCR products were electrophoresed on $8 \%$ polyacrylamide (acylamide/bisacrylamide, 37.5:1) gels containing a linear denaturant gradient of $25-50 \%$, with $100 \%$ denaturant defined as a solution of $7 \mathrm{M}$ urea and $40 \%(\mathrm{v} / \mathrm{v})$ deionized formamide. Electrophoresis was performed for $10 \mathrm{~min}$ at $200 \mathrm{~V}$ and subsequently for $16 \mathrm{~h}$ at $70 \mathrm{~V}$ in a $1 \mathrm{X}$ TAE buffer at a constant temperature of $60^{\circ} \mathrm{C}(10)$. Gels were stained with $\mathrm{AgNO}_{3}(19)$.

Stained gels were analyzed using Quantity One 4.6.2 gel analysis software (Bio-Rad). Similarities were displayed graphically as a dendrogram. The clustering algorithm used to construct the dendrograms was an unweighted pair group method with arithmetic mean (UPGMA) (20).

The Shannon-Wiener index of diversity $\left(H^{\prime}\right)(21)$ was used to determine the diversity of the bacterial community. This index was calculated using the following formula: $H^{\prime}=-\Sigma\left(p_{i}\right)\left(\ln p_{i}\right)$, where $p_{i}$ was the proportion of bands in the track and was calculated as follows: $p_{i}=n_{i} / \sum n_{i}$, where $n_{i}$ was the average density of peak $i$ in the densitometric curve. The evenness (E), which reflected uniformity of bacterial species distribution, was also calculated. This index was calculated by: $\mathrm{E}=H^{\prime} / \mathrm{lnS}$, where $\mathrm{S}$ was the number of bands.

Sequence analysis. To identify any separated and strong bands, the bands were cut from the polyacrylamide gel using a sterile scalpel. Gel fragments were eluted in $20 \mu \mathrm{l}$ distilled water overnight at $4^{\circ} \mathrm{C}$. Subsequent to this, the $4 \mu \mathrm{l}$ eluted DNA was reamplified by PCR following the aforementioned program but with $357 \mathrm{f}$ as the forward primer. Each PCR product was also subjected to DGGE analysis to confirm whether the band had been successfully purified. Following this, idiographic sequences were attained by Takara Biotechnology (Dalian) Co., Ltd. and the sequences were compared directly with those in GeneBank by basic local alignment search tool (BLAST; http://blast.ncbi.nlm.nih.gov/Blast.cgi) search (NCBI).

Statistical analysis. In vitro experiments to produce growth curves were performed in triplicate and the DGGE analyses were repeated at least three times. Statistical software SPSS version 17.0 (SPSS, Inc., Chicago, IL, USA) was used for analysis. P-values were determined by a t-test and $\mathrm{P}<0.01$ was considered to indicate a statistically significant difference.

\section{Results}

Isolation and purification of PPSB. Crude polysaccharide from the calyces of $P$. alkekengi var. francheti was extracted by hot water and ethanol precipitation with a yield of $13.6 \%$. Following deproteination using a combination of proteinase and the Sevag method, the crude polysaccharide sample was purified by a DEAE-52 Cellulose and Sephadex G-200 gel column. The main fraction (PPSB) was isolated for further analysis of physicochemical properties and intestinal microflora balance activities.

Physicochemical properties and chemical compositions. PPSB appeared as a white powder and had a negative response to the Bradford assay. No absorption was detected by UV spectrophotometery at 260 or $280 \mathrm{~nm}$. These observations showed an absence of nucleic acid and proteins in PPSB. A high-performance liquid chromatography profile indicated that PPSB had a single, symmetrical and sharp peak, therefore identifying PPSB as a homogeneous polysaccharide. In addition, the phenol sulfuric acid assay showed that PPSB contained $92.5 \%$ carbohydrate.

Growth curves. Fig. 1 shows the growth curves for nine PPSB concentrations of L. delbrueckii and Escherichia coli. Growth of $L$. delbrueckii was promoted by high concentrations of PPSB $(12.5-25.0 \mathrm{mg} / \mathrm{ml})$ only. E. coli growth was inhibited by all tested concentrations and bacteriostatic activity increased with increasing PPSB concentrations.

L.delbrueckii and E.coli are members of the Lactobacillaceae and Enterobacteriaceae families, respectively, which are typical, important intestinal microflora. Lactobacillaceae family members are probiotics (22), whereas Enterobacteriaceae family members are mainly regarded as opportunistic pathogens (23). 


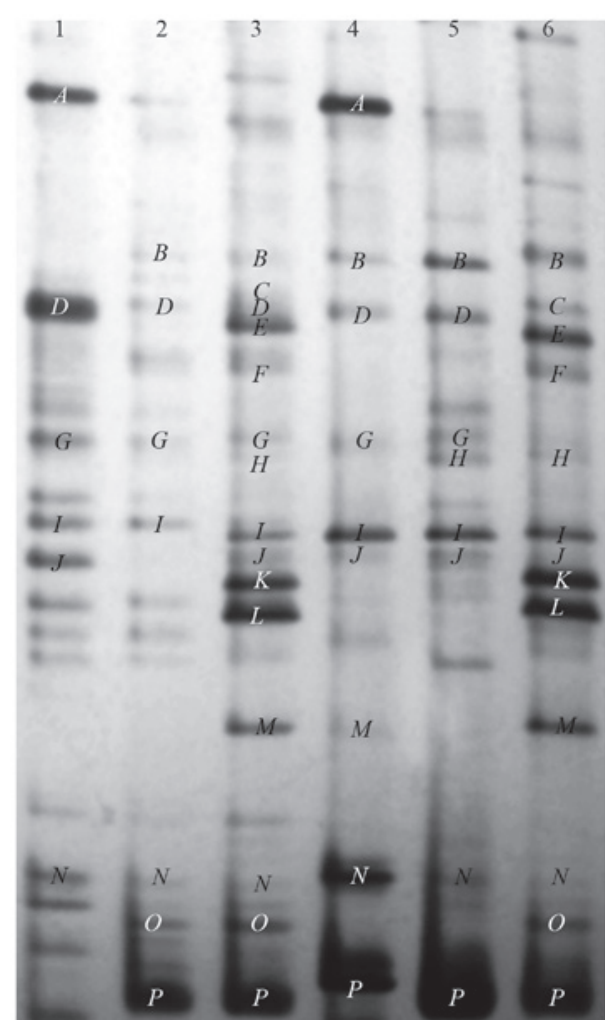

Figure 2. Representative denaturing gradient gel electrophoresis profiles of normal, levofloxacin-treated and P. alkekengivar. francheti polysaccharide $\mathrm{B}$ (PPSB)-treated treated mice. Lane 1, levofloxacin control, normal mice treated with levofloxacin; lane 2, PPSB-L, levofloxacin-treated mice with $50 \mathrm{mg} / \mathrm{kg}$ PPSB; lane 3 , PPSB-H, levofloxacin-treated mice with $100 \mathrm{mg} / \mathrm{kg}$ PPSB; lane 4, normal control, normal mice treated with water; lane 5, N-PPSB-L, normal mice with $50 \mathrm{mg} / \mathrm{kg}$ PPSB; lane 6 , N-PPSB-H, normal mice with $100 \mathrm{mg} / \mathrm{kg}$ PPSB.

Therefore, results of the present study demonstrate that PPSB has stimulatory effects on the growth of probiotic bacteria but inhibitory effects on the growth of pathogenic bacteria in vitro.

$D G G E$ analysis. The dominant intestinal microflora of $\mathrm{LC}$, PPSB-L, PPSB-H, NC, N-PPSB-L and N-PPSB-H groups was examined by DGGE analysis with universal primers targeting the $\mathrm{V} 3$ region of $16 \mathrm{~S}$ rRNA (Fig. 2). Lane 4 was the sample from the NC group, lane 1 contained the LC group, lanes 2 and 3 contained samples from the 50 and $100 \mathrm{mg} / \mathrm{kg}$ levofloxacin-treated groups, respectively, whilst lanes 5 and 6 contained samples from the normal mice treated with 50 and $100 \mathrm{mg} / \mathrm{kg}$ of PPSB, respectively. Band $A$ was present in the LC and NC groups but decreased markedly in intensity in other groups. The intensity of bands $C, H, O, E, K, L$ and $M$ increased markedly in groups PPSB-H and N-PPSB-H but were not present in the LC group. Other bands were observed in the majority of the groups, the intensities of which were similar between groups.

Clustering analysis based on Dice coefficient values was depicted in a UPGMA dendrogram and the general patterns of similarity among different groups were studied using Quantity One software (Bio-Rad). Fig. 3 demonstrates the significantly different clustering profiles formed by different groups. Three main clusters were identified in the dendrogram, the first involved the lane $1 \mathrm{LC}$ group, the second involved the lanes 4 and $5 \mathrm{NC}$ and N-PPSB-L groups and the third involved the lanes 2, 3 and 6 PPSB-L, PPSB-H and N-PPSB-H groups.

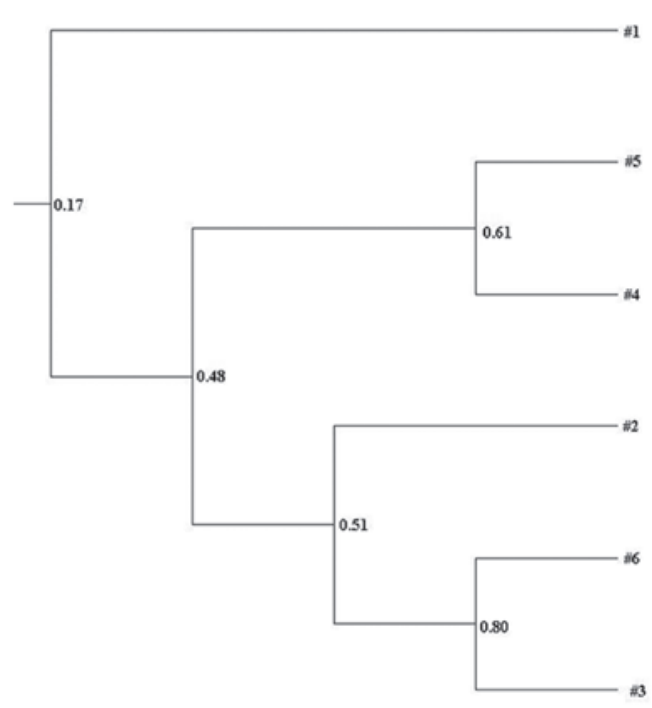

Figure 3. Unweighted pair group method with arithmetic mean dendrograms showing percentage of denaturing gradient gel electrophoresis profile matching of normal, levofloxacin-treated and P. alkekengivar. franchet polysaccharide B (PPSB)-treated treated mice. \#1: levofloxacin control, normal mice treated with levofloxacin; \#2: PPSB-L, levofloxacin-treated mice with $50 \mathrm{mg} / \mathrm{kg}$ PPSB; \#3: PPSB-H, levofloxacin-treated mice with $100 \mathrm{mg} / \mathrm{kg}$ PPSB; \#4: normal control, normal mice treated with water; \#5: N-PPSB-L, normal mice with $50 \mathrm{mg} / \mathrm{kg}$ PPSB; \#6: N-PPSB-H, normal mice with $100 \mathrm{mg} / \mathrm{kg}$ PPSB.

DGGE profiles showed the typical characteristics of general bacteria in the intestinal tract. Each band is likely to be derived from one phylogenetically distinct community and thus the total number of bands in the DGGE profile may provide an estimation of species number (24). The Shannon-Wiener index values of $H^{\prime}$, reflecting the structural diversity of the bacterial community (21), were calculated from the number and relative intensities of bands on the gel (Table II).

LC, PPSB-L, PPSB-H and N-PPSB-H group diversity indexes were shown to increase significantly compared with the NC group. The number of bands present in LC, PPSB-L, PPSB-H and N-PPSB-H groups was also greater compared with the NC group.

Data in Table III shows the closest relatives based on results of BLAST searches using DNA sequences obtained from DGGE gel bands identified by cluster analysis. Bands in the same position but in different lanes were excised and sequenced to confirm that they had the same identity (data not shown). $C, O$ and $H$ were sequenced and identified as Lactobacillus gasseri, reuteri and amylolyticus of the Lactobacillus genus with similarities of 100, 91 and $98 \%$, respectively. Bands for these three bacteria increased in number in the PPSB-H and N-PPSB-H groups, while there was no band distinguishable at the corresponding position in other groups, notably from the LC group. A was sequenced and identified as Enterococcus faecium of the Enterococcus genus with a similarity of $99 \%$. Band $A$ was present in LC and $\mathrm{NC}$ groups and at a lower band intensity in other groups. $J, K$, $L, M$ and $N$ were sequenced and identified as Prevotella micans, amnii, dentails, buccae and sp. of the Prevotella genus with similarities of 98, 99, 97, 94 and 96\%, respectively. $D, F$ and $I$ were sequenced and identified as Helicobacter bilis, cinaedi and hepaticus of the Helicobacter genus with similarities of 95 , 96 and $97 \%$, respectively. $B, E, G$ and $P$ were sequenced and 
Table II. Microflora diversity index analyses (mean \pm standard deviation; $n=10$ ).

\begin{tabular}{lcrr}
\hline Group & $\mathrm{S}$ & $H^{\prime \mathrm{b}}$ & $\mathrm{E}^{\mathrm{c}}$ \\
\hline NC & $11.6 \pm 0.9$ & $2.1607 \pm 0.0203$ & $0.8720 \pm 0.0497$ \\
LC & $18.4 \pm 1.1^{\mathrm{a}}$ & $2.8158 \pm 0.0145^{\mathrm{a}}$ & $0.9653 \pm 0.0176$ \\
PPSB-L & $15.7 \pm 1.3^{\mathrm{a}}$ & $2.4160 \pm 0.0154^{\mathrm{a}}$ & $0.8621 \pm 0.0187$ \\
PPSB-H & $19.8 \pm 0.9^{\mathrm{a}}$ & $2.6538 \pm 0.0773^{\mathrm{a}}$ & $0.9096 \pm 0.0011$ \\
N-PPSB-L & $11.1 \pm 2.2$ & $2.1556 \pm 0.0386$ & $0.9198 \pm 0.0384$ \\
N-PPSB-H & $16.8 \pm 1.5^{\mathrm{a}}$ & $2.7070 \pm 0.0098^{\mathrm{a}}$ & $0.9564 \pm 0.0247$
\end{tabular}

${ }^{\mathrm{a}} P<0.01$ vs. the control group. ${ }^{\mathrm{b}} H^{\prime}=-\sum\left(p_{i}\right)\left(\ln p_{i}\right) ; p_{i}$, proportion of bands in track; $p_{i}=n_{i} / \sum n_{i} ; n$, average density of peak $i$ in densitometric curve; ${ }^{\mathrm{c}} \mathrm{E}=H^{\prime} / \mathrm{lnS} ; \mathrm{S}$, number of bands. NC, normal mice treated with water; LC, normal mice treated with levofloxacin; P. alkekengivar. francheti polysaccharide B (PPSB)-L, levofloxacin-treated mice with $50 \mathrm{mg} / \mathrm{kg}$ PPSB; PPSB-H, levofloxacin-treated mice with $100 \mathrm{mg} / \mathrm{kg}$ PPSB; N-PPSB-L, normal mice with $50 \mathrm{mg} / \mathrm{kg}$ PPSB; N-PPSB-H, normal mice with $100 \mathrm{mg} / \mathrm{kg}$ PPSB.

Table III. Sequences of PCR amplicons derived from denaturing gradient gel electrophoresis gels and identities based on the BLAST database.

\begin{tabular}{|c|c|c|c|}
\hline $\begin{array}{l}\text { Selected } \\
\text { band }\end{array}$ & $\begin{array}{l}\text { Most similar sequence relative } \\
\text { (GenBank accession number) }\end{array}$ & Bacteria genus & Identity, \% \\
\hline A & Enterococcus faecium (AJKH01000109.1) & Enterococcus & 99 \\
\hline $\mathrm{B}$ & Akkermansia muciniphila (NC 010655.1) & Akkermansia & 94 \\
\hline $\mathrm{E}$ & Alistipes putredinis (ABFK02000016.1) & Alistipes & 90 \\
\hline $\mathrm{G}$ & Odoribacter splanchnicus (NC 015160.1) & Odoribacter & 96 \\
\hline $\mathrm{C}$ & Lactobacillus gasseri (ADFT01000001.1) & Lactobacillus & 100 \\
\hline $\mathrm{O}$ & Lactobacillus reuteri (CACS02000061.1) & & 91 \\
\hline $\mathrm{H}$ & Lactobacillus amylolyticus (ADNY01000006.1) & & 98 \\
\hline $\mathrm{D}$ & Helicobacter bilis (ACDN01000023.1) & Helicobacter & 95 \\
\hline $\mathrm{F}$ & Helicobacter cinaedi (ABQT01000054.1) & & 96 \\
\hline I & Helicobacter hepaticus (NC 004917.1) & & 97 \\
\hline $\mathrm{J}$ & Prevotella micans (AGWK01000061.1) & Prevotella & 98 \\
\hline $\mathrm{K}$ & Prevotella amnii (ADFQ01000002.1) & & 99 \\
\hline $\mathrm{L}$ & Prevotella dentails (AFPW01000057.1) & & 97 \\
\hline M & Prevotella buccae (AEPD01000042.1) & & 94 \\
\hline $\mathrm{N}$ & Prevotella sp. (ACZS01000106.1) & & 96 \\
\hline $\mathrm{P}$ & Bacteroides coprosuis (AFFW01000002.1) & Bacteroides & 98 \\
\hline
\end{tabular}

identified as Akkermansia muciniphila, Alistipes putredinis, Odoribacter splanchnicus and Bacteroides coprosuis with similarities of 94, 90, 96 and $98 \%$, respectively.

DGGE analysis indicated that levofloxacin has an important effect on the intestinal microflora of mice. An increased diversity of bacterial composition in LC, PPSB-L, PPSB-H and N-PPSB-H groups was found and may be associated with bacterial growth in levofloxacin-/PPSB-treated groups. Bacterial composition and structure were divided into three clusters for each of the different groups. The intestinal microflora communities of PPSB-H and N-PPSB-H groups demonstrated a relatively high homology. The results from sequencing provided more precise information to confirm the intestinal bacterial compositions of different groups. Bacteria belonging to the Bacteroides, Lactobacillus, Helicobacter, Prevotella, Enterococcus, Odoribacter, Alistipes and Akkermansia genera were dominant organisms in the intestinal tract of mice when analyzed by DGGE analysis. It is likely that the transformation of dominant organisms may be a risk factor associated with the side effects of antibiotics. Specifically, in the present study, the levofloxacin-treated group showed decreased Lactobacillus levels and increased Enterococcus levels. In addition, as the dose of PPSB increased, Lactobacillus and Prevotella noticeably increased in terms of number of species and quantity. These observations indicate that Lactobacillus growth may be promoted by PPSB in vivo, consistent with the results in vitro.

\section{Discussion}

The abuse of antibiotics has become a worldwide public health problem as unnecessary use of antibiotics is a major cause of the development of antibiotic-resistant bacterial strains (25). 
Side effects affecting the gastrointestinal tract, including abdominal pain, diarrhea and astriction, are common $(26,17)$. Non-pathogenic diarrhea is caused by an imbalance of intestinal microflora in the majority of cases. Once the intestinal microflora balance is disturbed, pathogenic bacteria, viruses and coccidia may easily infect the host.

Probiotics are live microorganisms that positively affect the colonization and composition of intestinal microflora and have stimulatory effects on the digestive processes and the immunity of the host (27). Lactobacillus spp. (28,29), B. subtilis and S. cerevisiae (30) are probiotics with positive effects on gastrointestinal microflora. However, probiotics are not currently administered with antibiotics, but various other methods have been used for improving the intestinal microflora balance, for example the use of prebiotics (31). An increasing number of studies $(31,32)$ have indicated that traditional Chinese medicines have been used as prebiotics for improving host immunity and are pivotal in the improvement of intestinal microflora balance.

In the present study, PPSB compounds, the main components of P. alkekengi var. francheti, were identified as the active compounds, which promote the number of species and quantity of Lactobacillus in vitro and in vivo. Intestinal microflora imbalances caused by antibiotics may induce pathogenic diseases and it has been suggested that an improvement in the intestinal microflora, for example an increase in the quantity of Lactobacillus and Bifidobacterium, may aid in the recovery from pathogenic diseases. The intestinal microflora composition produced from the present study indicates that the side effects of antibiotics are associated with the entire intestinal microflora composition rather than with the action of a single bacteria. As the dose of PPSB increased, Lactobacillus and Prevotella levels increased but those of Enterococcus markedly decreased in terms of quality and quantity, which was in accordance with known probiotic characteristics. Thus PPSB may be considered as a potential candidate for developing a novel agent that is able to improve the intestinal microflora balance.

\section{Acknowledgements}

This study was supported by a 973 project from the National Basic Research Program of China (project no. 2007CB513006).

\section{References}

1. Ge Y, Duan Y, Fang G, Zhang Y and Wang S: Study on biological activities of Physalis alkekengi var. francheti polysaccharide. J Sci Food Agr 89: 1593-1598, 2009.

2. Vessal M, Mehrani HA and Omrani GH: Effects of an aqueous extract of Physalis alkekengi fruit on estrus cycle, reproduction and uterine creatine kinase BB-isozyme in rats. J Ethnopharmacol 34: 69-78, 1991

3. Vessal M, Rasti M and Kooshesh F: Modulation of the pituitary and basomedial hypothalamic lysylaminopeptidase activities by beta-estradiol and/or an aqueous extract of Physalis alkekengi fruits. Comp Biochem Physiol B Biochem Mol Biol 115: 267-271, 1996.

4. Tong H, Liang $\mathrm{Z}$ and Wang G: Structural characterization and hypoglycemic activity of a polysaccharide isolated from the fruit of Physalis alkekengi L. Carbohydr Polym 71: 316-323, 2008.

5. Ge Y, Duan Y, Fang G, Zhang Y and Wang S: Polysaccharides from fruit calyx of Physalis alkekengi var. francheti: Isolation, purification, structural features and antioxidant activities. Carbohydr Polym 77: 188-193, 2009.

6. Fromin N, Hamelin J, Tarnawski S, et al: Statistical analysis of denaturing gel electrophoresis (DGE) fingerprinting patterns. Environ Microbiol 4: 634-643, 2002.
7. van der Gast CJ, Whiteley AS, Lilley AK, Knowles CJ and Thompson IP: Bacterial community structure and function in a metalworking fluid. Environ Microbiol 5: 453-461, 2003.

8. McBain AJ, Bartolo RG, Catrenich CE, Charbonneau D, Ledder RG and Gilbert P: Effects of triclosan-containing rinse on the dynamics and antimicrobial susceptibility of in vitro plaque ecosystems. Antimicrob Agents Chemother 47: 3531-3538, 2003.

9. Pharmacopeia of the People's Republic of China. Chemical Industry Press, Beijing, pp250-251, 2005.

10. Muyzer G, de Waal EC and Uitterlinden AG: Profiling of complex microbial populations by denaturing gradient gel electrophoresis analysis of polymerase chain reaction-amplified genes coding for 16S rRNA. Appl Environ Microbiol 59: 695-700, 1993.

11. Zhao W, Li JJ, Yue SQ, Zhang LY and Dou KF: Antioxidant activity and hepatoprotective effect of a polysaccharide from Bei Chaihu (Bupleurum chinense DC). Carbohydr Polym 89: 448-452, 2012.

12. Staub AM: Removal of protein-Sevag method. Meth Carbohydr Chem 5: 5-6, 1965.

13. Tan RX: Analysis of plant composition. Science Press in China, Beijing, pp76-78, 2002 (In Chinese).

14. DuBois M, Gilles KA, Hamilton JK, Rebers PA and Smith F: Colorimetric method for determination of sugars and related substances. Anal Chem 28: 350-356, 1956.

15. Bradford MM: A rapid and sensitive method for the quantitation of microgram quantities of protein utilizing the principle of protein-dye binding. Anal Biochem 72: 248-254, 1976.

16. Gutierrez J, Barry-Ryan C and Bourke P: The antimicrobial efficacy of plant essential oil combinations and interactions with food ingredients. Int J Food Microbiol 124: 91-97, 2008.

17. Li XL, Wu DC, Zhang CL and Xin Y: Effects of levofloxacin hydrochloride on the intestinal microbiota of BALB/c mice by PCR-DGGE. Afr J Microbiol Res 6: 3455-3460, 2012.

18. Ledder RG, Gilbert P, Huws SA, et al: Molecular analysis of the subgingival microbiota in health and disease. Appl Environ Microbiol 73: 516-523, 2007.

19. Edenborn SL and Sexstone AJ: DGGE fingerprinting of culturable soil bacterial communities complements culture-independent analyses. Soil Biol Biochem 39: 1570-1579, 2007.

20. Du H, Jiao N, Hu Y and Zeng Y: Real-time PCR for quantification of aerobic anoxygenic phototrophic bacteria based on puf $\mathrm{M}$ gene in marine environment. J Exp Mar Biol Ecol 329: 113-121, 2006.

21. Gafan GP, Lucas VS, Roberts GJ, Petrie A, Wilson M and Spratt DA: Statistical analyses of complex denaturing gradient gel electrophoresis profiles. J Clin Microbiol 43: 3971-3978, 2005.

22. Cruywagen CW, Jordaan I and Venter L: Effect of Lactobacillus acidophilus supplementation of milk replacer on preweaning performance of calves. J Dairy Sci 79: 483-486, 1996.

23. Liu J, Wu D, Ahmed A, et al: Comparison of the gut microbe profiles and numbers between patients with liver cirrhosis and healthy individuals. Curr Microbiol 65: 7-13, 2012.

24. Hu Q, Qi HY, Zeng JH and Zhang HX: Bacterial diversity in soils around a lead and zinc mine. J Environ Sci (China) 19: 74-79, 2007.

25. Bia P, Tong SL and Parton KA: Family self-medication and antibiotics abuse for children and juveniles in a Chinese city. Soc Sci Med 50: 1445-1450, 2000

26. Sprandel KA and Rodvold KA: Safety and tolerability of fluoroquinolones. Clin Cornerstone (Suppl 3): S29-S36, 2003.

27. Choi JY, Shinde PL, Ingale SL, et al: Evaluation of multi-microbe probiotics prepared by submerged liquid or solid substrate fermentation and antibiotics in weaning pigs. Livest Sci 138: 144-151, 2011.

28. Abe F, Ishibashi $\mathrm{N}$ and Shimamura S: Effect of administration of bifidobacteria and lactic acid bacteria to newborn calves and piglets. J Dairy Sci 78: 2838-2846, 1995.

29. Guerra NP, Bernárdez PF, Méndez J, Cachaldora P and Pastrana Castro L: Production of four potentially probiotic lactic acid bacteria and their evaluation as feed additives for weaned piglets. Anim Feed Sci Tech 134: 89-107, 2007.

30. Mathew AG, Chattin SE, Robbins CM and Golden DA: Effects of a direct-fed yeast culture on enteric microbial populations, fermentation acids, and performance of weaning pigs. J Anim Sci 76: 2138-2145, 1998

31. Ishihara N, Chu DC, Akachi S and Juneja LR: Improvement of intestinal microflora balance and prevention of digestive and respiratory organ diseases in calves by green tea extracts. Livest Prod Sci 68: 217-229, 2001.

32. Koropatkin NM, Cameron EA and Martens EC: How glycan metabolism shapes the human gut microbiota. Nat Rev Microbiol 10: 323-335, 2012. 